\title{
Both HCV Infection and Elevated Liver Stiffness Significantly Impacts on Several Parameters of T-Cells Homeostasis in HIV-Infected Patients
}

\author{
Clara Restrepo ${ }^{1,2, \dagger}{ }^{\text {, Beatriz Álvarez }}{ }^{3, \dagger}{ }^{\text {, José L Valencia }}{ }^{4}$, Marcial García ${ }^{1,2}$, \\ María A Navarrete-Muñoz ${ }^{1,2}$, José M Ligos ${ }^{5}$, Alfonso Cabello ${ }^{3}{ }^{[0}$, Laura Prieto ${ }^{3}$, Sara Nistal ${ }^{2}$, \\ María Montoya ${ }^{5}$, Miguel Górgolas ${ }^{3}$, Norma Rallón ${ }^{1,2, *}+\mathbb{( D}$ and José M Benito ${ }^{1,2,+}+\mathbb{D}$ \\ 1 HIV and Viral Hepatitis Research Laboratory, Instituto de Investigación Sanitaria Fundación Jiménez Díaz, \\ Universidad Autónoma de Madrid (IIS-FJD, UAM), 28933 Madrid, Spain; clararestrepog@gmail.com (C.R.); \\ marcial_g_a@hotmail.com (M.G.); mangelesnm94@gmail.com (M.A.N.-M.); jbenito1@hotmail.com (J.M.B.) \\ 2 Hospital Universitario Rey Juan Carlos, Móstoles, 28933 Madrid, Spain; sara.nistal@hospitalreyjuancarlos.es \\ 3 Hospital Universitario Fundación Jiménez Díaz, 28040 Madrid, Spain; BAlvarez@quironsalud.es (B.Á.); \\ acabello@fjd.es (A.C.); LPrietoPe@fjd.es (L.P.); mgorgolas@fjd.es (M.G.) \\ 4 Departamento de Estadística e Investigación Operativa III, Facultad de Estudios Estadísticos, \\ Universidad Complutense de Madrid, 28040 Madrid, Spain; joseval@estad.ucm.es \\ 5 Centro Nacional de Investigaciones Cardiovasculares (CNIC), 28029 Madrid, Spain; \\ jmligos@gmail.com (J.M.L.); mmontoya@cnic.es (M.M.) \\ * Correspondence: norma.rallon@fjd.es; Tel.: +34-91-544-37-20; Fax: +34-91-550-48-49 \\ + Authors contributed equally.
}

Received: 23 August 2020; Accepted: 11 September 2020; Published: 15 September 2020 updates

\begin{abstract}
Background: The role of hepatitis C virus (HCV) co-infection on the T-cell homeostasis disturbances in human immunodeficiency virus (HIV)-infected patients as well as its reversion after $\mathrm{HCV}$ eradication with direct acting antivirals (DAAs) therapy has not been yet clarified. We extensively analyzed the effect of HCV co-infection on immune parameters of HIV pathogenesis and its evolution after HCV eradication with DAAs. (2) Methods: Seventy individuals were included in the study-25 HIV-monoinfected patients, $25 \mathrm{HIV} / \mathrm{HCV}$-coinfected patients and $20 \mathrm{HIV}$ and HCV seronegative subjects. All patients were on antiretroviral therapy and undetectable HIV-viremia. Immune parameters, such as maturation, activation, apoptosis, senescence and exhaustion of T-cells were assessed by flow cytometry. Cross-sectional and longitudinal (comparing pre- and post-DAAs data in HIV/HCV coinfected patients) analyses were performed. Univariate and multivariate (general linear model and canonical discriminant analysis -CDA-) analyses were used to assess differences between groups. (3) Results-The CDA was able to clearly separate HIV/HCV coinfected from HIV-monoinfected patients, showing a more disturbed T-cells homeostasis in HIV/HCV patients, especially activation and exhaustion of T-cells. Interestingly, those perturbations were more marked in $\mathrm{HIV} / \mathrm{HCV}$ patients with increased liver stiffness. Eradication of $\mathrm{HCV}$ with DAAs restored some but not all the T-cells homeostasis disturbances, with activation and exhaustion of effector CD8 T-cells remaining significantly increased three months after HCV eradication. (4) Conclusions- $\mathrm{HCV}$ co-infection significantly impacts on several immune markers of HIV pathogenesis, especially in patients with increased liver stiffness. Eradication of HCV with DAAs ameliorates but does not completely normalize these alterations. It is of utmost relevance to explore other mechanisms underlying the immune damage observed in $\mathrm{HIV} / \mathrm{HCV}$ coinfected patients with control of both HIV and $\mathrm{HCV}$ replication.
\end{abstract}

Keywords: HIV/HCV coinfection; T-cell homeostasis disturbances; liver stiffness; immune restoration; DAAs-based therapy 


\section{Introduction}

The UNAIDS (Joint United Nations Programme on HIV and AIDS) estimates that around 37.9 million people were living with human immunodeficiency virus (HIV) in 2018 [1] and 71 million people were chronically infected with hepatitis $C$ virus $(\mathrm{HCV})$ [2]. Since both viruses are transmitted by contaminated blood products, around 2.3 million people are coinfected with HIV and HCV [2] and the main risk groups are people who inject drugs (PWID) followed by men who have sex with men (MSM) [3-5]. Co-infection poses an additional stress on host immune system and, as a consequence, each virus can aggravate the normal clinical course of the concomitant infection. It is well known the negative impact of HIV on the HCV progression-higher levels of HCV load [6], faster liver disease progression $[7,8]$ and hepatocellular carcinoma (HCC) [9]. All these clinical conditions improve with the use of antiretroviral therapy (ART) with a reduction of HCV viral load, better liver-related survival and lower rates of fibrosis development $[8,10,11]$. Studies on the potential effect of HCV on clinical progression of HIV are scarcer and more controversial [12-15].

The effect of HCV on immune parameters of HIV infection pathogenesis has also been analyzed. Most previous studies have focused on T cell activation and apoptosis [16-22], some of them reporting discordant results [20-22]. Other aspects of HIV pathogenesis such as T cell exhaustion, senescence, maturation and thymic function have been less explored in HIV/HCV co-infection [18,22-25]. In a large cohort of HIV/HCV patients naive for both anti-HCV treatment and for ART and using a cross-sectional design, we found that HIV pathogenesis was significantly affected by HCV, specially activation and exhaustion of CD8 T-cells [26].

The impact of HCV on HIV pathogenesis has also been explored in cohorts of HIV/HCV patients undergoing anti-HCV treatment. Most previous studies have analyzed only a limited number of parameters, focusing mainly on $T$ cell activation $[17,27,28]$ or apoptosis [21], in cohorts of patients undergoing anti-HCV treatment with IFN- $\alpha$ and ribavirin and thus the results obtained maybe biased by the immunomodulatory effect of IFN- $\alpha$ [29]. The current therapy for HCV, based on the use of direct acting antivirals (DAAs) without any immunomodulatory effect and with very high potency to eradicate HCV [30], brings us the opportunity to better clarify the role of HCV on HIV pathogenesis. For this purpose, herein we have performed an in-depth analysis of several immune parameters related to HIV infection pathogenesis, in a well-defined cohort of HIV/HCV coinfected patients before and after HCV eradication with the new DAAs-based therapy.

\section{Experimental Section}

\subsection{Study Population}

Patients included in the study were recruited from the infectious diseases outpatient clinic of Hospital Universitario Fundación Jiménez Díaz, Madrid. Two groups were included-twenty-five HIV patients coinfected with HCV (HIV/HCV group) and 25 HIV monoinfected patients (HIV group). Twenty age and sex-matched HIV and HCV-seronegative individuals from blood banking were included as seronegative controls (SNC group), as a reference group for the T-cells subsets evaluated. Inclusion criteria for HIV group were-adults ( $>18$ years of age) with chronic HIV infection, being on ART and having undetectable plasma HIV-RNA for at least 12 months prior to inclusion. Inclusion criteria for HIV/HCV group were the same as those for HIV group and also to have chronic active HCV infection (positive HCV serology and detectable levels of plasma HCV-RNA) and being eligible for anti-HCV treatment with IFN $\alpha$ /ribavirin-free DAAs-based regimens. All subjects included in the study signed a written informed consent and the study protocol was approved by the ethical committee of the Hospital Universitario Fundación Jiménez Díaz (PIC 46/2015, record number 07/15 dated on 14 April 2015). 


\subsection{Cell Samples}

EDTA-anticoagulated blood was obtained by venipuncture and peripheral blood mononuclear cells (PBMCs) were immediately isolated by density gradient centrifugation using Ficoll-Hypaque (Sigma Chemical Co., St. Louis, MO, USA) and frozen in fetal calf serum (FCS) plus $10 \%$ dimethyl sulfoxide (DMSO). For HIV patients and seronegative controls a single sample was obtained at the moment of inclusion. For HIV/HCV group two different samples were obtained-at the moment of inclusion before starting anti-HCV treatment (pre-DAAs HIV/HCV group) and 3 months after the end of treatment, when sustained virological response (SVR) is evaluated (post-DAAs HIV/HCV group). Cryopreserved PBMCs were employed for immunophenotypic analysis. Viability of thawed PBMCs was always greater than $85 \%$.

\subsection{Immunophenotypic Analysis}

Multiparameter flow cytometry was employed to analyze the expression levels of 182 unique T-cells subsets. PBMCs were stained with a panel of thirteen different monoclonal antibodies that in combination defined a total of 182 unique $T$ cell subsets. The following parameters were analyzed in CD4 and CD8 T cells-maturation (measuring CD45RA and CCR7 expression), activation (measuring CD38 and HLADR expression), exhaustion (measuring PD1 and Tim3 expression), senescence (measuring CD28 and CD57 expression), apoptosis (measuring CD28 and CD95 expression), recent thymic emigrants (measuring CD31 expression). The complete list of monoclonal antibodies and fluorochromes used in the study is shown in Supplementary Table S1. The staining procedure and flow cytometry analysis are described in Supplementary Methods and a representative example of flow cytometry analysis is shown in Supplementary Figure S1. The complete list of all $\mathrm{T}$ cell subsets analyzed with their levels of expression in the different study groups are shown in Supplementary Table S2.

\subsection{Statistical Analysis}

The main characteristics of the study groups were expressed as median [interquartile range] or as proportion and the comparisons between groups were done using Mann-Whitney U-test or chi-squared test as appropriate. Inter and intra-group differences in the levels of $\mathrm{T}$ cell subsets were tested using a univariate analysis (Kruskall-Wallis test, Mann-Whitney U test and Wilcoxon signed-rank test as appropriate) and the effect of different covariates was adjusted using a general linear model (GLM). Moreover, a partial least square regression (PLS) was employed to reduce the dimensionality of data followed by a canonical discriminant analysis to separate between different groups of subjects (HIV patients, HIV/HCV patients and SNC individuals) and between different timepoints (pre and post-therapy in HIV/HCV patients). A detailed description of discriminant analysis is given in Supplementary Methods.

\section{Results}

\subsection{Characteristics of Patients Included in the Study}

The main characteristics of patients at the time of inclusion in the study are shown in Table 1. All HIV/HCV patients were naïve for anti-HCV therapy at the time of inclusion. There were no significant differences between HIV and HIV/HCV groups in terms of age, gender, time since HIV diagnosis, time on ART, CD4 counts and HIV transmission route. The group of seronegative controls (SNC) was matched with the groups of patients for age (46 (43-51) years, $p=0.175$ for the global comparison between the study groups) and for gender (100\% of SNC donors were male, $p=0.24$ for the comparison between SNC and HIV groups). AST and ALT hepatic enzymes were significantly higher in HIV/HCV patients, whereas total cholesterol and LDL were significantly higher in HIV patients. Liver stiffness was $<7.1 \mathrm{KPa}$ in $60 \%$ of patients and $>7.1 \mathrm{KPa}$ in $40 \%$. According to the study by Cástera et al. [31], this cut-off of 7.1 KPa separates between F0-F1 $(<7.1 \mathrm{KPa})$ stages of the Metavir fibrosis scale (no significant fibrosis) and F2-F4 (>7.1 KPa) stages of Metavir scale (significant fibrosis). 
Regarding the DAAs combinations used, because all HIV/HCV coinfected patients were recruited between 2015-2018 and according to the DAAs combinations available on those dates for the treatment of $\mathrm{HCV}$ genotypes 1 and 4, the majority of patients received the combination of grazoprevir/elbasvir ( $64 \%$ of them), followed by the combination of sofosbuvir/ledipasvir ( $32 \%$ of them) with only one patient $(4 \%)$ receiving the combination of ombitasvir/paritaprevir/ritonavir/dasabubir.

Table 1. Characteristics at baseline of patients included in the study.

\begin{tabular}{|c|c|c|c|}
\hline Characteristic & HIV Group $(n=25)$ & HIV/HCV Group $(n=25)$ & $p$-Value \\
\hline Age (years) & $48(42-55)$ & $44(39-48)$ & 0.11 \\
\hline Gender ( $\%$ of males) & $88 \%$ & $100 \%$ & 0.24 \\
\hline Time since HIV diagnosis (years) & $9(6-14)$ & $7(2-10)$ & 0.07 \\
\hline Time since HCV diagnosis (years) & NA & $2(1.5-5)$ & NA \\
\hline Time on ART (years) & $5(3.5-7.5)$ & $4(2-9)$ & 0.63 \\
\hline CD4 count (cells/ $\mu \mathrm{L})$ & $816(605-992)$ & 735 (577-902) & 0.31 \\
\hline Ratio CD4/CD8 & $0.84(0.56-1.34)$ & $0.75(0.60-1.09)$ & 0.49 \\
\hline ALT level (IU/L) & $32(24-37)$ & $74(49-162)$ & $<0.0001$ \\
\hline AST level (IU/L) & $27(22-31)$ & $58(37-122)$ & $<0.0001$ \\
\hline GGT level (IU/L) & $36(22-54)$ & $55(25-119)$ & 0.06 \\
\hline Total cholesterol level (mg/dL) & $194(162-227)$ & $157(125-177)$ & $<0.0001$ \\
\hline HDL level $(\mathrm{mg} / \mathrm{dL})$ & $42(37-50)$ & $46(33-50)$ & 0.815 \\
\hline LDL level (mg/dL) & $119(93-146)$ & $85(71-104)$ & 0.001 \\
\hline HCV-RNA (log copies/mL) & NA & $6.1(5.8-6.4)$ & NA \\
\hline HIV transmission route (\%) & & & 1 \\
\hline Sexual & $100 \%$ & $96 \%$ & \\
\hline Parenteral & $0 \%$ & $4 \%$ & \\
\hline HCV genotype (\%) & & & NA \\
\hline $1 \mathrm{a}$ & NA & $60 \%$ & \\
\hline $1 b$ & NA & $12 \%$ & \\
\hline 4 & NA & $28 \%$ & \\
\hline $\begin{array}{c}\text { Liver stiffness } \\
\text { (measured by elastography) (\%) }\end{array}$ & & & NA \\
\hline$<7.1 \mathrm{KPa}$ & NA & $60 \%$ & \\
\hline$\geq 7.1 \mathrm{KPa}$ & NA & $40 \%$ & \\
\hline \multicolumn{4}{|l|}{ DAA regimen } \\
\hline GZR/EBR & NA & $64 \%$ & \\
\hline SOF/LDV & NA & $32 \%$ & \\
\hline $\mathrm{OBV} / \mathrm{PTV} / \mathrm{r} / \mathrm{DSV}$ & NA & $4 \%$ & \\
\hline
\end{tabular}

ART: antiretroviral therapy; ALT: alanine aminotransferase; AST: aspartate aminotransferase; GGT: gamma glutamil transferase; HDL: high density lipoprotein; LDL: low density lipoprotein; HCV: hepatitis C virus. Data for continuous variables are given as median (interquartile range). Significant $p$-values are in bold. NA: not applicable; KPa: kilopascals. DAAs: direct-acting antivirals; GZR: grazoprevir; EBR: elbasvir; SOF: sofosbuvir; LDV: ledipasvir; OBV: ombitasvir; PTV: paritaprevir, r: ritonavir; DSV: dasabuvir

\subsection{HCV Co-Infection Significantly Impacts on T-Cells Homeostasis}

To evaluate the role of $\mathrm{HCV}$ co-infection on immune parameters of HIV pathogenesis we compared the phenotypic profile of both CD4 and CD8 T-cells between HIV monoinfected and HIV/HCV coinfected patients before HCV eradication with the new DAAs-based therapy.

We first applied a univariate analysis to compare the expression levels of the different 182 studied T-cell subsets. This analysis showed that 43 unique T-cell subsets were differentially expressed between the different groups of studied individuals. As expected, the majority of these T-cell subsets presented significant differences between SNC individuals and both groups of patients. However, there were a few T-cell subsets significantly different between HIV and pre-DAAs HIV/HVC patients (Supplementary Table S3), within them it is important to highlight different CD4 and CD8 T-cell subsets expressing markers associated to the activation and exhaustion phenomena, with a significantly higher level of expression in the group of pre-DAAs HIV/HCV patients (Figure 1). Then, we used a 
multivariate general linear model (GLM) analysis to confirm the differences in the expression levels of the different studied T-cell subsets between HIV and pre-DAAs HIV/HCV patients, adjusting by different covariates (age, time since HIV diagnosis, time on ART, CD4 count, percentage of CD4, percentage of CD8). This analysis showed that levels of both exhaustion and activation of effector CD4 T-cells were significantly increased in pre-DAAs HIV/HCV patients compared to HIV patients, in agreement with the results of the univariate analysis (Supplementary Table S4).
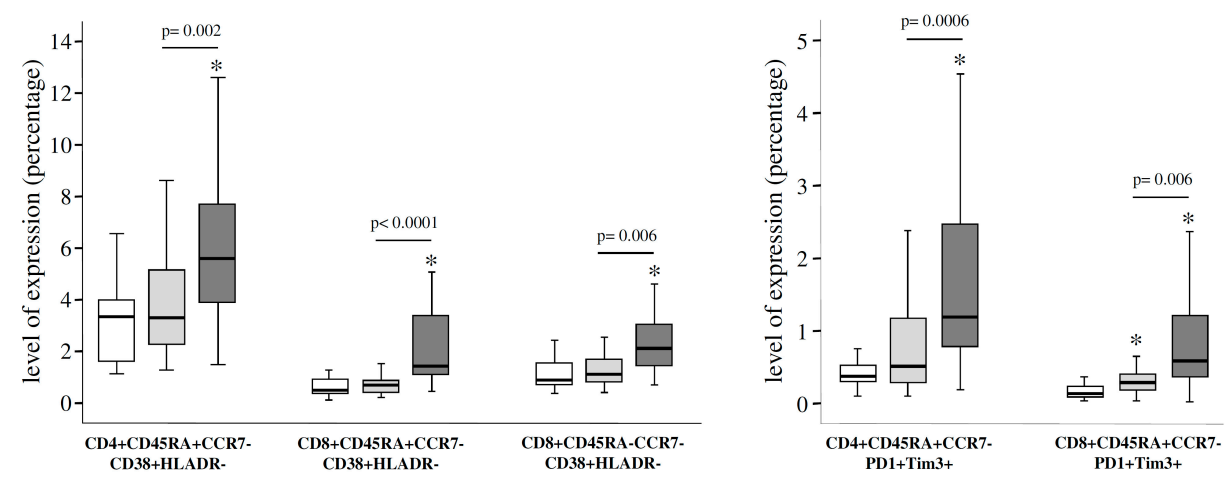

Figure 1. Box-plots showing differences in the level of expression for several CD4 and CD8 T-cell subsets between seronegative controls (white boxes), human immunodeficiency virus (HIV) monoinfected patients (light-grey boxes) and pre-direct acting antivirals (DAAs) HIV/ hepatitis C virus (HCV) coinfected patients (dark-grey boxes). $p$-values for the comparison between monoinfected and coinfected patients are shown. An asterisk $\left(^{*}\right)$ indicates significant difference $(p<0.05)$ compared to seronegative controls by Mann-Whitney U test.

Additionally, a canonical discriminant analysis (CDA) was carried out to find the variables (T-cell subsets) that maximize the separation between studied groups. A detailed description of the results obtained in this analysis is shown in Supplementary Results S1. Seronegative controls (SNC individuals group) were clearly separated from both groups of HIV-infected patients. However, there was also a good separation between HIV and pre-DAAs HIV/HCV patients. Moreover, HIV patients were closer to seronegative controls than were pre-DAAs HIV/HCV patients (Figure 2). Mean \pm SD values for canonical function 1 (Can1) in the different groups of individuals were-2.42 $\pm 0.85 ;-0.46 \pm 1.05$; $-1.43 \pm 1.06$ in seronegative controls, HIV patients and pre-DAAs HIV/HCV patients, respectively. According to the coefficients of the different T-cell subsets in the canonical functions, the T-cell subsets with the highest contribution to discriminate between HIV and pre-DAAs HIV/HCV groups were effector CD4 and effector CD8 T-cells expressing markers associated to activation and exhaustion. Levels of these subsets in pre-DAAs HIV/HCV and in HIV patients are shown in Table 2.

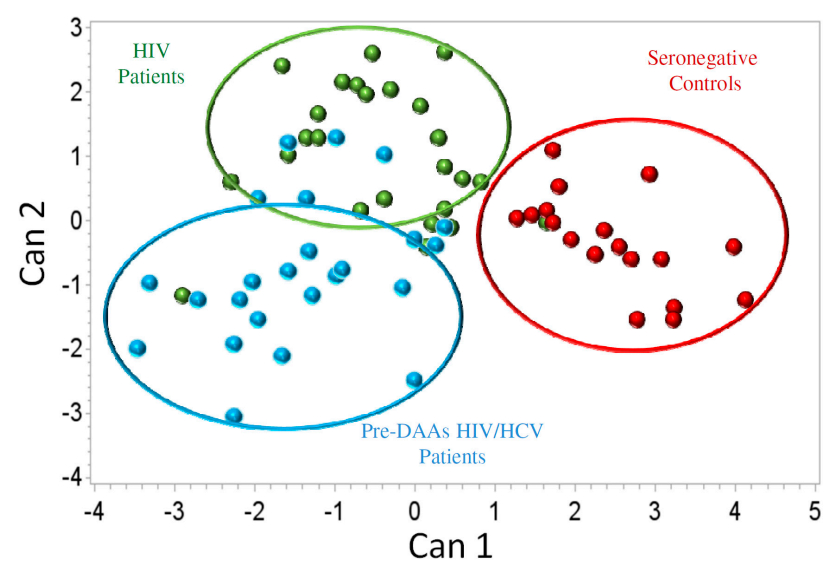

Figure 2. Canonical discriminant analysis comparing the phenotypic profile of $\mathrm{T}$ cells between HIV-monoinfected patients (green dots), pre-DAAs HIV/HCV coinfected patients (blue dots) and seronegative controls (red dots). 
Table 2. Levels of different T-cell subsets in HIV/HCV coinfected patients before DAAs treatment (pre-DAAs) compared to HIV monoinfected patients.

\begin{tabular}{cccc}
\hline \multirow{2}{*}{ T-Cell Subsets } & \multicolumn{2}{c}{$\begin{array}{c}\text { Level of T-Cell Subsets } \\
\text { Median [IQR] }\end{array}$} & $p$-Value * \\
\cline { 2 - 4 } & $\begin{array}{c}\text { pre-DAAs HIV/HCV } \\
\text { Coinfected Patients }\end{array}$ & HIV Monoinfected Patients & \\
\hline CD4+CD45RA+CCR7-PD1-TIM3+ & $0.91(0.45-1.57)$ & $0.46(0.27-0.74)$ & 0.076 \\
\hline CD4+CD45RA+CCR7-CD38+HLADR- & $5.59(3.84-8.83)$ & $3.29(2.19-0.47)$ & 0.004 \\
\hline CD8+CD45RA+CCR7-PD1+TIM3+ & $0.59(0.31-1.25)$ & $0.29(0.18-0.44)$ & 0.006 \\
\hline CD8+CD45RA+CCR7-CD38+HLADR- & $1.41(1.01-3.66)$ & $0.67(0.39-0.91)$ & $<0.0001$ \\
\hline & $* p$-values of comparison between groups by Mann-Whitney U test. &
\end{tabular}

\subsection{The Degree of Liver Stiffness Significantly Impacts on T-Cells Homeostasis}

The potential impact of liver stiffness (LS) on the levels of the different studied T-cell subsets in the distinct studied group of patients was evaluated. The univariate analysis (Kruskall-Wallis test) revealed that several T-cell subsets, mainly activation and exhaustion of CD4 and CD8 T-cells, presented significant differences when comparing HIV patients, pre-DAAs HIV/HCV patients with LS $\geq 7.1 \mathrm{KPa}$ and pre-DAAs HIV/HCV patients with LS $<7.1 \mathrm{KPa}$. Interestingly, when compared to HIV patients, the levels of the majority of these T-cell subsets were significantly different only in pre-DAAs HIV/HCV patients with LS $\geq 7.1 \mathrm{KPa}$ (Figure 3).

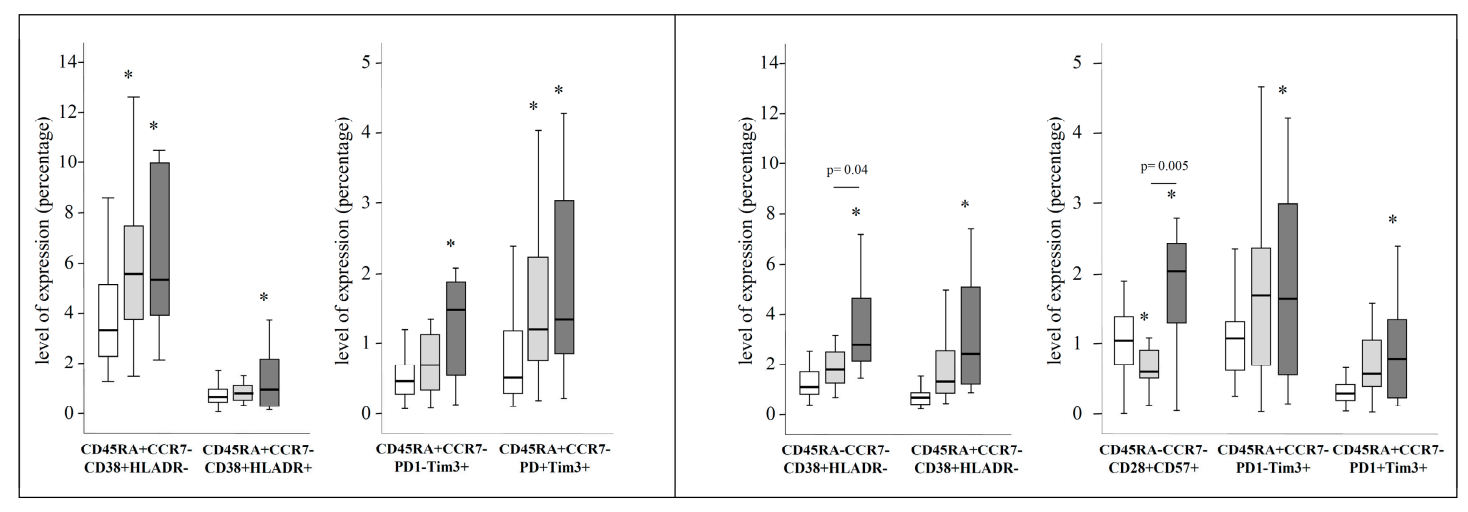

Figure 3. Box-plots showing differences in the level of expression for several CD4 (left graphs) and CD8 (right graphs) T-cell subsets between HIV monoinfected patients (white boxes), pre-DAAs HIV/HCV coinfected patients with liver stiffness (LS) $<7.1 \mathrm{Kpa}$ (light-grey boxes) and in pre-DAAs HIV/HCV coinfected patients with LS $\geq 7.1 \mathrm{KPa}$ (dark-grey boxes). $p$-values for the comparison between HIV/HCV with LS $<7.1 \mathrm{Kpa}$ and LS $\geq 7.1 \mathrm{KPa}$ are shown. An asterisk $\left(^{*}\right)$ indicates significant $(p<0.05)$ difference compared to HIV monoinfected patients by Mann-Whitney U test.

A multivariate general linear model (GLM) analysis, adjusting by different covariates (age, time since HIV diagnosis, time on ART, CD4 count, percentage of CD4, percentage of CD8), confirmed the influence of liver stiffness on the levels of both activation and exhaustion of effector CD4 and effectors CD8 T-cell subsets. For the majority of T-cell subsets, significant differences with respect to HIV patients were observed only in pre-DAAs HIV/HCV patients with LS $\geq 7.1 \mathrm{KPa}$ (Supplementary Table S5).

Lastly, a CDA analysis was performed to ascertain the ability of the studied variables (T-cell subsets) to discriminate between HIV patients and the two groups of pre-DAAs HIV/HCV patients ( $\mathrm{LS} \geq 7.1 \mathrm{KPa}$ and LS $<7.1 \mathrm{KPa}$ ). A detailed description of the results obtained in this analysis is shown in Supplementary Results S2. The results showed that pre-DAAs HIV/HCV patients with LS $\geq 7.1 \mathrm{KPa}$ were clearly separated from the other two groups (HIV monoinfected and pre-DAAs HIV/HCV 
coinfected with LS $<7.1 \mathrm{KPa}$ ) that were close to each other (Figure 4). The T-cell subsets with the greatest weight in separating pre-DAAs HIV/HCV patients with LS $\geq 7.1 \mathrm{KPa}$ from the other two groups were effector CD4 and effector CD8 T-cells expressing markers of activation and exhaustion.

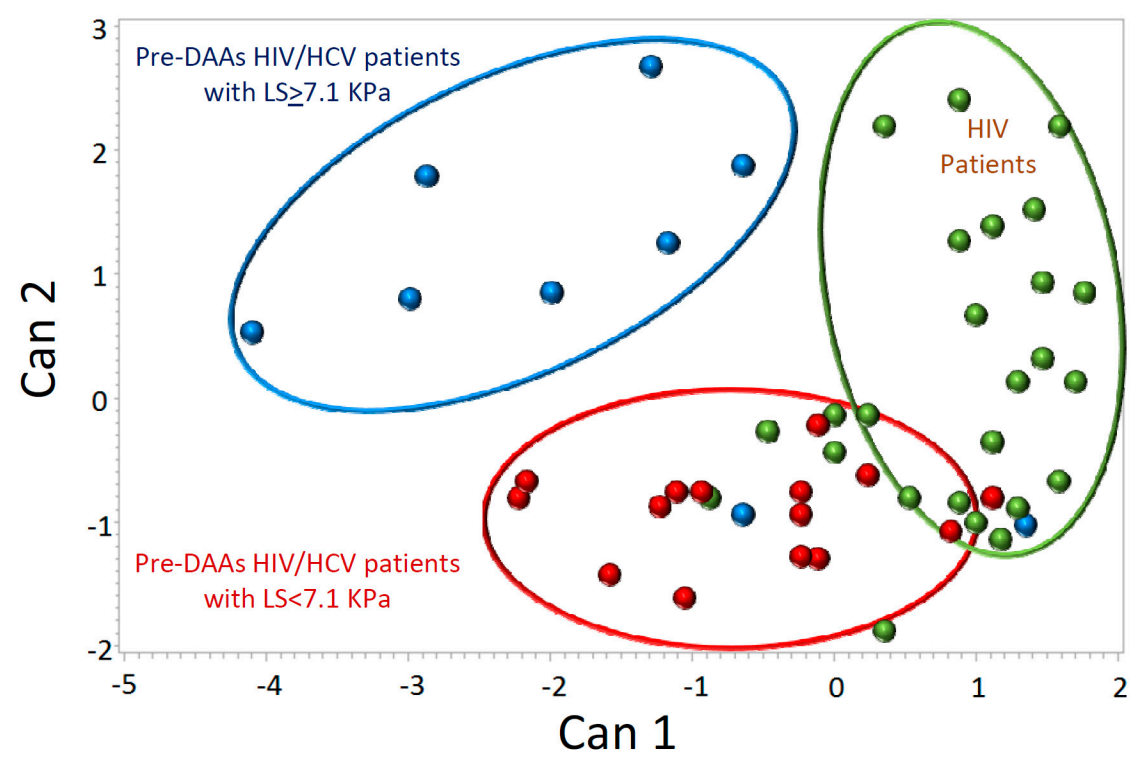

Figure 4. Canonical discriminant analysis comparing the phenotypic profile of T cells between HIV patients (green dots), pre-DAAs HIV/HCV coinfected patients with liver stiffness (LS) < 7.1 Kpa (red dots) and pre-DAAs HIV/HCV coinfected patients with LS $\geq 7.1 \mathrm{Kpa}$ (blue dots).

\subsection{HCV Eradication with DAAs Does Not Completely Revert T-Cells Homeostasis Disturbances}

All HIV/HCV patients reached sustained virological response after treatment with DAAs. In parallel, liver enzymes assessed at the time of SVR evaluation returned to normal levels (median(IQR): 18(16-26); 24(20-33); 16(13-25) IU/mL for ALT, AST and GGT respectively). Moreover, liver stiffness was $<7.1 \mathrm{KPa}$ in all patients after HCV eradication (after a follow-up median period of 25 months since liver stiffness was not assessed at the time of SVR for the majority of patients).

We evaluated to what extent the T-cells homeostasis disturbances observed in pre-DAAs HIV/HCV patients (before HCV eradication) were reverted after HCV eradication (post-DAAs HIV/HCV patients) to values similar to those found in HIV monoinfected patients. We first analyzed the evolution of T-cells subsets that were significantly different in pre-DAAs HIV/HCV patients compared to HIV patients and found that after HCV eradication some of them but not all experienced a significant variation. Thus, exhaustion and activation of effector CD4 T-cells as well as activation of effector memory CD8 T-cells significantly decreased, returning to levels similar to those of HIV patients. However, exhaustion and activation of effector CD8 T-cells did not significantly change after DAAs treatment (Supplementary Table S6). In agreement with this, both activation and exhaustion of effector CD8 T-cells remained increased in post-DAAs HIV/HCV patients compared to HIV monoinfected patients (Figure 5). Moreover, the canonical discriminant analysis showed some degree of separation between HIV monoinfected patients and post-DAAs HIV/HCV patients (Figure 6). A detailed description of the results obtained in this analysis is shown in Supplementary Results S3. Interestingly, the T-cell subsets that most influenced the separation between HIV and post-DAAs HIV/HCV groups were both exhaustion and activation of effector CD8 T-cells, in agreement with the results of the univariate analysis. Levels of these subsets in post-DAAs HIV/HCV and in HIV patients are shown in Table 3. 


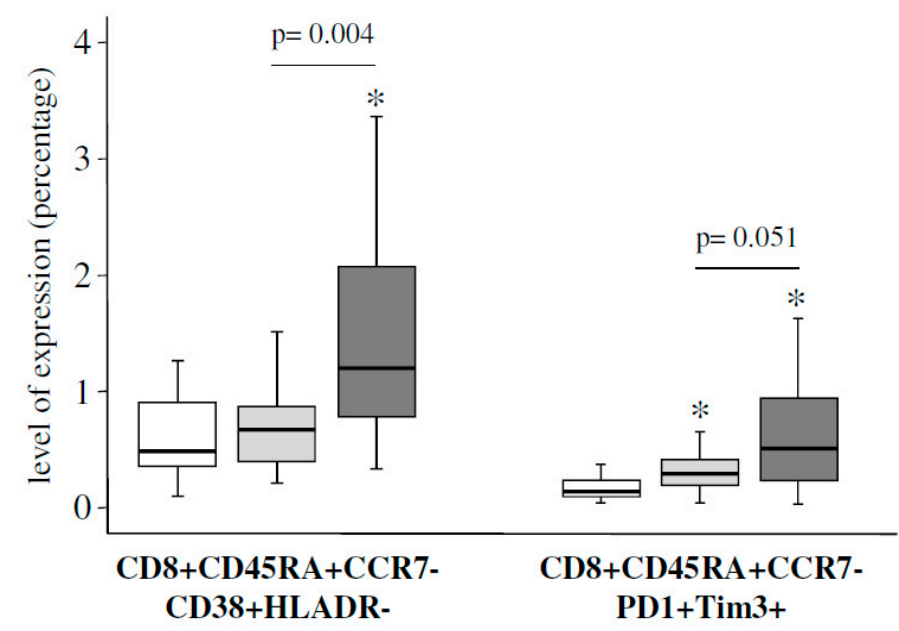

Figure 5. Box-plots showing differences in the level of expression for different CD8 T-cell subsets between seronegative controls (white boxes), HIV monoinfected patients (light-grey boxes) and post-DAAs HIV/HCV coinfected patients (dark-grey boxes). $p$-values for the comparison between monoinfected and coinfected patients are shown. An asterisk $\left(^{*}\right)$ indicates significant $(p<0.05)$ difference compared to seronegative controls by Mann-Whitney $U$ test.

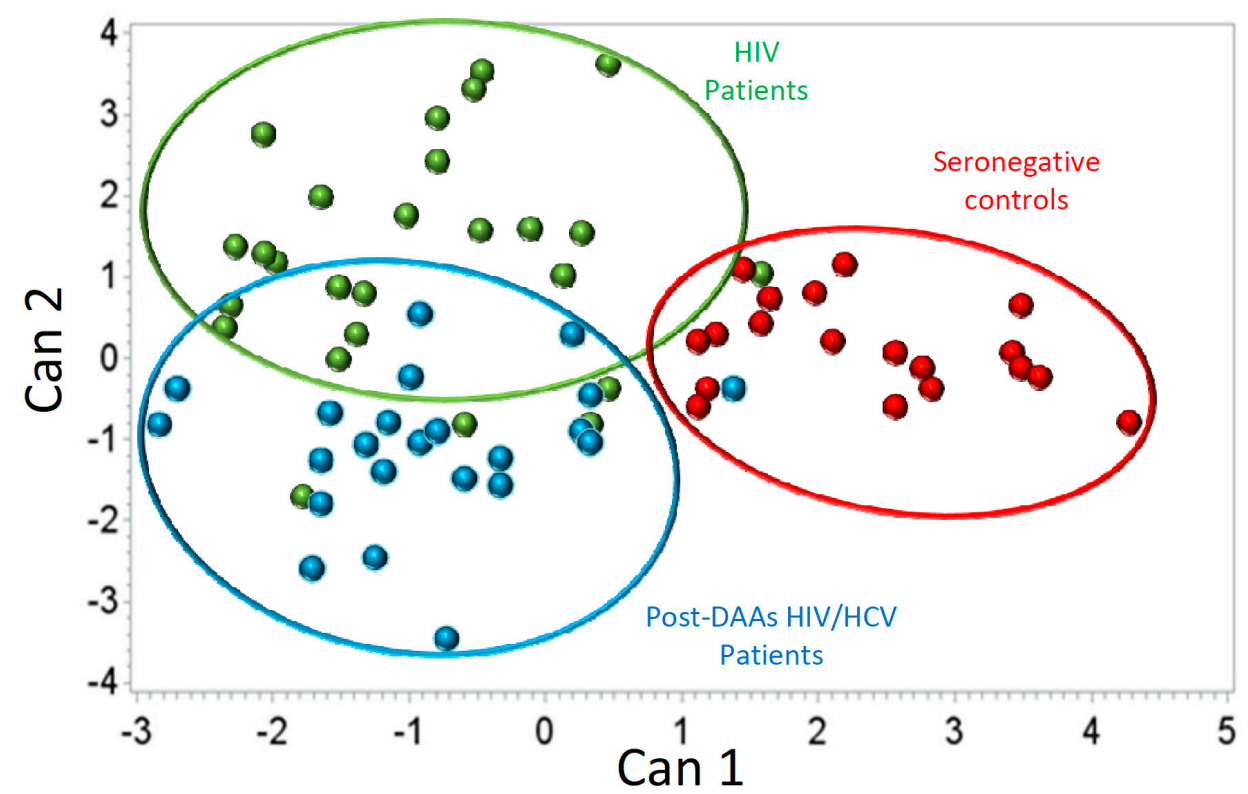

Figure 6. Canonical discriminant analysis comparing the phenotypic profile of $\mathrm{T}$ cells between HIV-monoinfected patients (green dots), post-DAAs HIV/HCV coinfected patients (blue dots) and seronegative controls (red dots).

Table 3. Levels of different T-cell subsets in HIV/HCV coinfected patients after DAAs treatment (post-DAAs) compared to HIV monoinfected patients.

\begin{tabular}{cccc}
\hline \multirow{2}{*}{ T-Cell Subsets } & \multicolumn{2}{c}{$\begin{array}{c}\text { Level of T-Cell Subsets } \\
\text { Median [IQR] }\end{array}$} & $p$-Value * \\
\cline { 2 - 3 } & $\begin{array}{c}\text { post-DAAs HIV/HCV } \\
\text { Coinfected Patients }\end{array}$ & HIV Monoinfected Patients & \\
\hline CD8+CD45RA+CCR7-PD1+TIM3+ & $0.51(0.23-0.99)$ & $0.29(0.18-0.44)$ & 0.051 \\
\hline CD8+CD45RA+CCR7-CD38+HLADR- & $1.20(0.77-2.51)$ & $0.67(0.39-1.58)$ & 0.003 \\
\hline${ }^{*} p$-values of comparison between groups by Mann-Whitney U test. &
\end{tabular}




\section{Discussion}

The main findings of our study are-(a) the presence of HCV coinfection significantly impacts on several immune parameters in patients with HIV infection, especially on T-cells activation and exhaustion; (b) The impact on immune parameters is more marked in HIV/HCV coinfected patients with increased liver stiffness; (c) eradication of HCV with DAAs-based therapy does not completely restore the T-cells homeostasis perturbations observed in $\mathrm{HIV} / \mathrm{HCV}$ coinfected patients.

Our study shows that coinfection with HCV in HIV-infected patients significantly impacts on T-cells homeostasis, in agreement with previous studies [16-26]; however, our study differs from the previous studies in several aspects-(a) we analyzed a very homogeneous population of HIV patients, all on long-term successful ART and with high CD4 counts; (b) we performed an in-depth characterization of several parameters of T-cells homeostasis; (c) we applied a statistical analysis that enabled us to detect subtle but relevant differences in the profile of T-cells homeostasis between HIV and HIV/HCV patients; (d) the anti-HCV treatment for all included HIV/HCV coinfected patients was the new DAAs-based therapy, IFN $\alpha /$ ribavirin-free-based regimens; thus avoiding the bias of the immunomodulatory effect of IFN- $\alpha$.

Firstly, we show that in spite of long-term suppression of HIV replication and high CD4 counts, the profile of T-cells homeostasis in the whole population of HIV patients clearly departs from that of seronegative controls, demonstrating that restoration of T-cells homeostasis is no complete even after several years of complete suppression of HIV replication and high CD4 counts, a finding that is in agreement with previous reports [32]. However, our study is the first showing that this impairment of T-cells homeostasis affects to several processes including activation, exhaustion, senescence and apoptosis of both CD4 and CD8 T-cells.

Secondly, we found that, in the canonical discriminant analysis, HIV/HCV patients formed a cluster clearly separated not only from seronegative controls but also from HIV patients. Moreover, the cluster of HIV/HCV patients was more separated from the cluster of seronegative controls than was the cluster of HIV patients, supporting that HCV coinfection increases the perturbations of T-cells homeostasis associated to HIV infection. Of note, both the canonical and the univariate and multivariate analyses pointed to activation and exhaustion of effector populations of T-cells as the most important to discriminate between HIV/HCV coinfected and HIV monoinfected patients. These results are in agreement with previous studies showing a significant impact of HCV coinfection on T-cells activation $[16,17,33-35]$ and/or exhaustion $[18,24]$. Similar results were found in a recent study by our group employing a cohort of patients with untreated HIV infection, suggesting that in the setting of HIV infection, HCV impacts on T-cells homeostasis independently of the level of HIV replication [26].

T-cells activation and exhaustion are important factors in the pathogenesis of HIV disease and thus, the increases we observed in coinfected patients may potentially have relevant clinical implications. Activation of CD8 T-cells has a central role in HIV progression as has been extensively reported [36]. More recently, T-cells exhaustion has been shown as another important factor involved in HIV disease progression, both in cross-sectional [37] and longitudinal [38,39] studies. Interestingly, the increase in expression of exhaustion markers that we found in HIV/HCV coinfected patients was restricted to the effector subset of T-cells, what could impact on the anti-viral activity of these cells because exhaustion of T-cells is a pivotal mechanism of virus escape from immune response in HIV [40] and in HCV [41] infections.

Another interesting finding of our study was the association of the degree of liver stiffness (LS) with perturbations of T-cells homeostasis, an aspect that has been scarcely addressed. Only two previous studies have explored the association between T-cells activation and the degree of LS in $\mathrm{HIV} / \mathrm{HCV}$ co-infection and have reported an increase in activation in patients with increased values of LS [35,42]. Our study confirms and extends these previous observations, showing perturbations not only in activation but also in exhaustion, which is another important aspect of T-cells homeostasis. Although activation and exhaustion of effector T-cells were the most relevant subsets associated to the degree of LS in our study, the discriminant analysis suggests the existence of subtle perturbations 
in many other aspects of T-cells homeostasis in HIV/HCV patients with LS $\geq 7.1 \mathrm{KPa}$, including senescence of effector memory CD8 T-cells and apoptosis of naïve CD4 T-cells. These perturbations of T-cells homeostasis could be involved in the development of liver damage since immune activation and systemic inflammation have been proposed as drivers of hepatic injury [43,44].

Curiously, both activation and exhaustion of effector CD8 T-cells remained significantly increased in HIV/HCV patients after HCV eradication (3 months after the end of DAAs-therapy, SVR) compared to HIV patients. In agreement, the discriminant analysis showed some separation between HIV monoinfected patients and post-DAAs HIV/HCV coinfected patients, supporting that eradication of $\mathrm{HCV}$ with DAAs-based therapy is not able to completely revert T-cells homeostasis disturbances, at least in the short term. An explanation that may account for this finding is that normalization of T-cells homeostasis may take longer than the follow up period evaluated in our study (3 months after the end of DAAs-therapy, when sustained virological response, SVR, is evaluated), as has been shown in the context of HIV infection after ART. In fact, several T-cells homeostasis disturbances persisted in the whole population of HIV patients analyzed in our study in spite of several years of ART and complete suppression of HIV replication. Further studies with longer follow-up are needed to ascertain if T-cells homeostasis disturbances associated to HCV coinfection are completely restored over time after HCV eradication with DAAs-based therapy.

There are some controversial issues in our study. First, the relatively small sample size that might preclude detecting more differences associated with the presence of HCV in HIV/HCV coinfected patients. However, the sophisticated statistical analysis that we employed including canonical discriminant analyses was able to overcome this limitation to a large extent since this statistical approach allowed us to detect subtle but important differences in variables that maximize the separation between studied groups. In fact we were able to clearly separate HIV/HCV coinfected patients from HIV monoinfected patients in spite of the relatively small sample size. Second, the interpretation of liver stiffness data should be done carefully because elastography is a technique that can be biased by the presence of necroinflammatory activity in the liver [45,46]. Thus, increased liver stiffness can reflect either fibrosis or necroinflammatory activity, being both conditions indicative of liver damage. Interestingly, in our study those HIV/HCV patients with liver stiffness $\geq 7.1 \mathrm{KPa}$ did also have higher values of the hepatic enzymes AST and ALT suggesting a higher degree of necroinflammatory activity. However, after HCV eradication with DAAs-based therapy (3 months after the end of DAAs-therapy, when sustained virological response, SVR, is evaluated) normal levels of the liver enzymes were observed. Furthermore, after a median follow-up of 25 months after the end of DAA-based therapy, liver stiffness was $<7.1 \mathrm{KPa}$ in all $\mathrm{HIV} / \mathrm{HCV}$ coinfected patients.

In summary, our study is the first addressing the impact of HCV co-infection on several aspects of T-cells homeostasis in a very homogenous population of HIV-infected patients. We used a robust methodology, both experimentally and statistically, that allowed us to address not only a broad spectrum of T-cell homeostasis parameters but also allowed us to detect any subtle difference in these parameters between the two study groups. We were able to identify the T-cell subsets (mainly effector CD4 and effector CD8 T-cells expressing markers associated to activation and exhaustion) with the highest contribution to discriminate between HIV monoinfected and HIV/HCV coinfected groups. Overall, our findings show a significant impact of $\mathrm{HCV}$ on several aspects of immune pathogenesis of HIV disease, especially in those patients with increased liver stiffness but this impact of HCV coinfection was not fully reversed (with activation and exhaustion of effector CD8 T-cells remaining significantly increased) after eradication of HCV with DAAs-based therapy. Thus, in the management of patients with HIV infection, particular attention should be paid to HIV/HCV coinfected patients, since there may be active pathogenic mechanisms despite the control of both HIV and HCV replication, which prompts the necessity to explore on other mechanisms underlying the immune damage observed.

Supplementary Materials: The following are available online at http://www.mdpi.com/2077-0383/9/9/2978/s1, Supplementary Methods; Supplementary Figure S1: Representative example of flow cytometry analysis. Dot-plots in the row (A) show the gating strategy employed to gate CD4+ and CD8+ T cells. The other two rows (B and C) 
show the phenotype of CD4+ and CD8+ T cells according to the different surface markers included in the staining panel to define different aspects of T cell homeostasis. Supplementary Figure S2: Fluorescence minus one (FMO) controls employed to set the gates defining positive versus negative population of cells for those markers with low and/or continuous expression. Gates for each marker were set on CD3+ T cells. Supplementary Results S1: Results of the PLS model and canonical discriminant analysis carried out to discriminate between seronegative controls (SNC), patients monoinfected with HIV (HIV) and patients coinfected with HIV and HCV before treatment with DAAs (pre-DAAs HIV/HCV). Supplementary Results S2: Results of the PLS model and canonical discriminant analysis carried out to discriminate between patients monoinfected with HIV (HIV), patients coinfected with HIV and HCV before treatment with DAAs and liver stiffness (LS) values < 7.1 KPa (pre-DAAs HIV/HCV with $\mathrm{KPa}<7.1$ ) and patients coinfected with HIV and HCV before treatment with DAAs and liver stiffness (LS) values > 7.1 KPa (pre-DAAs HIV/HCV with KPa > 7.1). Supplementary Results S3: Results of the PLS model and canonical discriminant analysis carried out to discriminate between seronegative controls (SNC), patients monoinfected with HIV (HIV) and patients coinfected with HIV and HCV after treatment with DAAs (post-DAAs HIV/HCV) Supplementary Table S1: Monoclonal antibodies and fluorochromes used in the study. Supplementary Table S2: List of T-cell subsets analyzed with their level of expression (median and interquartile range) in the different groups of individuals included in the study. Supplementary Table S3: T-cell subsets presenting statistically significant differences (in the univariate analysis) between the study groups (HIV group, pre-DAAs HIV/HCV group and SNC group/seronegative controls). In bold, T-cell subsets presenting significant differences $(p<0.017$ after adjusting for multiple comparisons) between HIV and pre-DAAs HIV/HCV groups. Supplementary Table S4: Multivariate Analysis (GLM): CD4 T-cell subsets with significant differences $(p<0.05)$, in their expression levels, between HIV and pre-DAAs HIV/HCV patients, after adjusting for several covariates. Table shows the coefficient and the adjusted p-value for the factor "patients group (HIV = 0, HIV/HCV $=1)$ " in the GLM analysis for each of the studied T-cell subsets. Supplementary Table S5: Multivariate Analysis (GLM): T-cell subsets with significant differences $(p<0.05)$, in their expression levels, between HIV patients, pre-DAAs HIV/HCV patients with liver stiffness (LS) $>7.1 \mathrm{KPa}$ and pre-DAAs HIV/HCV patients with $\mathrm{LS}<7.1 \mathrm{KPa}$, after adjusting for several covariates. Table shows the coefficients in the GLM analysis and the adjusted $p$-value for each of the studied T-cell subsets for pre-DAAs HIV/HCV patients with LS $>7.1 \mathrm{KPa}$ and for pre-DAAs HIV/HCV patients with LS $<7.1 \mathrm{KPa}$, taking as reference the HIV group. Supplementary Table S6: Levels of different T-cell subsets in HIV/HCV coinfected patients before DAAs treatment (pre-DAAs) and after DAAs treatment (post-DAAs). In bold, T-cell subsets presenting significant differences.

Author Contributions: Conceptualization: J.M.B. and N.R.; Data curation: B.Á., A.C., L.P., S.N. and M.G. (Miguel Górgolas); Formal analysis: B.A., J.M.B. and N.R.; Funding acquisition: J.M.B. and N.R.; Investigation: C.R., B.Á., M.G. (Marcial García), M.A.N.-M.; Methodology: B.Á., C.R., J.M.L., M.M.; Statistical analysis: J.L.V., N.R. and J.M.B.; Project administration: J.M.B. and N.R.; Supervision: J.M.B. and N.R.; Validation: J.M.B. and N.R.; Visualization: J.M.B. and N.R.; Writing-original draft: C.R. and B.Á.; Writing-review \& editing: J.M.B. and N.R. All authors have read and agreed to the published version of the manuscript.

Funding: The CNIC is supported by the Ministerio de Ciencia, Innovación y Universidades (MCNU) and the Pro CNIC Foundation and is a Severo Ochoa Center of Excellence (SEV-2015-0505). This work was partially supported by projects PI14/00518 and RD16/0025/0013 integrated in the Spanish plan for scientific and technical research and innovation from the General Sub-Directorate for research assessment and promotion, Spanish Carlos III Institute of Health (ISCIII) co-funded by the European Regional Development Fund (ERDF). Norma Rallón is a Miguel Servet investigator from the ISCIII (CPII19/00025). María A Navarrete-Muñoz is funded by project IND2018/BMD-9651. Clara Restrepo is funded by project RD16/0025/0013. Marcial García is co-funded by RD16/0025/0013 project and an intramural research scholarship from IIS-FJD.

Acknowledgments: We especially thank Victoria de Santisteban and Andrea García for their technical assistance. We would like to thank all patients and healthy donors who participated in the study.

Conflicts of Interest: The authors declare no conflict of interests.

\section{References}

1. Unaids.org. UNAIDS DATA 2019. Available online: https://www.unaids.org/en/resources/documents/2019/ 2019-UNAIDS-data (accessed on 15 February 2020).

2. WHO. Global Hepatitis Report 2017. Available online: https://www.who.int/hepatitis/publications/globalhepatitis-report2017/en/ (accessed on 15 February 2020).

3. Hernandez, M.D.; Sherman, K. HIV/hepatitis C coinfection natural history and disease progression. Curr. Opin. HIV AIDS 2011, 6, 478-482. [CrossRef]

4. Matthews, G.; Dore, G. HIV and hepatitis C coinfection. J. Gastroenterol. Hepatol. 2008, 23, 1000-1008. [CrossRef] [PubMed]

5. Ingiliz, P.; Rockstroh, J. Natural history of liver disease and effect of hepatitis $\mathrm{C}$ virus on HIV disease progression. Curr. Opin. HIV AIDS 2015, 10, 303-308. [CrossRef] 
6. Sherman, K.E.; O’Brien, J.; Gutierrez, A.G.; Harrison, S.; Urdea, M.; Neuwald, P.; Wilber, J. Quantitative Evaluation of Hepatitis C Virus RNA in Patients with Concurrent Human Immunodeficiency Virus Infections. J. Clin. Microbiol. 1993, 31, 2679-2682. [CrossRef]

7. Telfer, P.; Sabin, C.; Devereux, H.; Scott, F.; Dusheiko, G.; Lee, C. The progression of HCV-associated liver disease in a cohort of haemophilic patients. Br. J. Haematol. 1994, 87, 555-561. [CrossRef]

8. Benhamou, Y.; Bochet, M.; Di Martino, V.; Charlotte, F.; Azria, F.; Coutellier, A.; Vidaud, M.; Bricaire, F.; Opolon, P.; Katlama, C.; et al. Liver fibrosis progression in human immunodeficiency virus and hepatitis C virus coinfected patients. Hepatology 1999, 30, 1054-1058. [CrossRef]

9. Bräu, N.; Fox, R.; Xiao, P.; Marks, K.; Naqvi, Z.; Taylor, L.E.; Trikha, A.; Sherman, M.; Sulkowski, M.S.; Dieterich, D.T.; et al. North American Liver Cancer in HIV Study Group. Presentation and outcome of hepatocellular carcinoma in HIV-infected patients: A U.S.-Canadian multicenter study. J. Hepatol. 2007, 47, 527-537. [CrossRef]

10. Qurishi, N.; Kreuzberg, C.; Lüchters, G.; Effenberger, W.; Kupfer, B.; Sauerbruch, T.; Rockstroh, J.K.; Spengler, U. Effect of antiretroviral therapy on liver-related mortality in patients with HIV and hepatitis C virus coinfection. Lancet 2003, 362, 1708-1713. [CrossRef]

11. Thein, H.; Yi, Q.; Dore, G.; Krahn, M. Natural history of hepatitis C virus infection in HIV-infected individuals and the impact of HIV in the era of highly active antiretroviral therapy: A meta-analysis. AIDS 2008, 22, 1979-1991. [CrossRef]

12. Sulkowski, M.S.; Moore, R.D.; Mehta, S.H.; Chaisson, R.E.; Thomas, D.L. Hepatitis C and progression of HIV disease. JAMA 2002, 288, 199-206. [CrossRef]

13. Rockstroh, J.K.; Mocroft, A.; Soriano, V.; Tural, C.; Losso, M.H.; Horban, A.; Kirk, O.; Phillips, A.; Ledergerber, B.; Lundgren, J. EuroSIDA Study Group. Influence of hepatitis $\mathrm{C}$ virus infection on HIV-1 disease progression and response to highly active antiretroviral therapy. J. Infect. Dis. 2005, 192, 992-1002. [CrossRef]

14. D' Arminio Monforte, A.; Cozzi-Lepri, A.; Castagna, A.; Antinori, A.; De Luca, A.; Mussini, C.; Caputo, S.L.; Arlotti, M.; Magnani, G.; Pellizzer, G.; et al. Icona Foundation Study Group. Risk of developing specific AIDS-defining illnesses in patients coinfected with HIV and hepatitis $C$ virus with or without liver cirrhosis. Clin. Infect. Dis. 2009, 49, 612-622. [CrossRef] [PubMed]

15. Van der Helm, J.; Geskus, R.; Sabin, C.; Meyer, L.; Del Amo, J.; Chêne, G.; Dorrucci, M.; Muga, R.; Porter, K.; Prins, M. CASCADE Collaboration in EuroCoord. Effect of HCV infection on cause-specific mortality after HIV seroconversion, before and after 1997. Gastroenterology 2013, 144, 751-760. [CrossRef]

16. Kovacs, A.; Karim, R.; Mack, W.J.; Xu, J.; Chen, Z.; Operskalski, E.; Frederick, T.; Landay, A.; Voris, J.; Spencer, L.S.; et al. Activation of CD8 T cells predicts progression of HIV infection in women coinfected with hepatitis C virus. J. Infect. Dis. 2010, 201, 823-834. [CrossRef]

17. Gonzalez, V.D.; Falconer, K.; Blom, K.G.; Reichard, O.; Mørn, B.; Laursen, A.L.; Weis, N.; Alaeus, A.; Sandberg, J.K. High levels of chronic immune activation in the T-cell compartments of patients coinfected with hepatitis $C$ virus and human immunodeficiency virus type 1 and on highly active antiretroviral therapy are reverted by alpha interferon and ribavirin treatment. J. Virol. 2009, 83, 11407-11411. [CrossRef]

18. Feuth, T.; Arends, J.E.; Fransen, J.H.; Nanlohy, N.M.; van Erpecum, K.J.; Siersema, P.D.; Hoepelman, A.I.; van Baarle, D. Complementary role of HCV and HIV in T-cell activation and exhaustion in HIV/HCV coinfection. PLoS ONE 2013, 8, e59302. [CrossRef]

19. Korner, C.; Kramer, B.; Schulte, D.; Coenen, M.; Mauss, S.; Fätkenheuer, G.; Oldenburg, J.; Nattermann, J.; Rockstroh, J.K.; Spengler, U. Effects of HCV coinfection on apoptosis of CD4+ T-cells in HIV-positive patients. Clin. Sci. (Lond.) 2009, 116, 861-870. [CrossRef]

20. Nuñez, M.; Soriano, V.; López, M.; Ballesteros, C.; Cascajero, A.; González-Lahoz, J.; Benito, J.M. Coinfection with Hepatitis C Virus Increases Lymphocyte Apoptosis in HIV-Infected Patients. Clin. Infect. Dis. 2006, 43, 1209-1212. [CrossRef]

21. Laskus, T.; Kibler, K.V.; Chmielewski, M.; Wilkinson, J.; Adair, D.; Horban, A.; Stańczak, G.; Radkowski, M. Effect of hepatitis C virus on HIV-induced apoptosis. PLoS ONE 2013, 8, e75921. [CrossRef]

22. Schmagel, K.V.; Saidakova, E.V.; Korolevskaya, L.B.; Shmagel, N.G.; Chereshnev, V.A.; Anthony, D.D.; Lederman, M.M. Influence of hepatitis $C$ virus coinfection on CD4+ T cells of HIV-infected patients receiving HAART. AIDS 2014, 28, 2381-2388. [CrossRef] 
23. Korolevskaya, L.; Shmagel, K.; Saidakova, E.; Shmagel, N.; Slobodchikova, S.; Chereshnev, V. Effect of Hepatitis C Virus Coinfection on the Content of CD4+ and CD8+ T Cell Subpopulations in HIV-Infected Patients Receiving Antiretroviral Therapy. Bull. Exp. Biol. Med. 2016, 161, 281-283. [CrossRef] [PubMed]

24. Saha, B.; Choudhary, M.; Sarin, S. Expression of inhibitory markers is increased on effector memory T cells during hepatitis $\mathrm{C}$ virus/HIV coinfection as compared to hepatitis C virus or HIV monoinfection. AIDS 2013, 27, 2191-2200. [CrossRef] [PubMed]

25. Grady, B.; Nanlohy, N.; van Baarle, D. HCV monoinfection and HIV/HCV coinfection enhance T-cell immune senescence in injecting drug users early during infection. Immun. Ageing 2016, 13, 10. [CrossRef] [PubMed]

26. Rallón, N.; García, M.; García-Samaniego, J.; Rodríguez, N.; Cabello, A.; Restrepo, C.; Álvarez, B.; García, R.; Górgolas, M.; Benito, J.M. HCV coinfection contributes to HIV pathogenesis by increasing immune exhaustion in CD8 T-cells. PLoS ONE 2017, 12, e0173943. [CrossRef]

27. Massanella, M.; Tural, C.; Papagno, L.; Garcia, E.; Jou, A.; Bofill, M.; Autran, B.; Clotet, B.; Blanco, J. Changes in T-cell subsets in HIV-HCV-coinfected patients during pegylated interferon- $\alpha 2 \mathrm{a}$ plus ribavirin treatment. Antivir. Therapy 2010, 15, 333-342. [CrossRef]

28. Marchetti, G.; Nasta, P.; Bai, F.; Gatti, F.; Bellistrì, G.M.; Tincati, C.; Borghi, F.; Carosi, G.; Puoti, M.; Monforte, A.D. Circulating sCD14 is associated with virological response to pegylated-interferon-alpha/ribavirin treatment in HIV/HCV co-infected patients. PLoS ONE 2012, 7, e32018. [CrossRef]

29. Thomas, H.; Foster, G.; Platis, D. Mechanisms of action of interferon and nucleoside analogues. J. Hepatol. 2003, 39, S93-S98. [CrossRef]

30. Sikavi, C.; Chen, P.; Lee, A.; Saab, E.; Choi, G.; Saab, S. Hepatitis C and Human Immunodeficiency Virus Co-Infection in the Era of Direct-Acting Antiviral Agents: No Longer A Difficult to Treat Population. Hepatology 2018, 67, 847-857. [CrossRef]

31. Castéra, L.; Vergniol, J.; Foucher, J.; Le Bail, B.; Chanteloup, E.; Haaser, M.; Darriet, M.; Couzigou, P.; De Lédinghen, V. Prospective comparison of transient elastography, Fibrotest, APRI, and liver biopsy for the assessment of fibrosis in chronic hepatitis C. Gastroenterology 2005, 128, 343-350. [CrossRef]

32. Wilson, E.M.P.; Sereti, I. Immune restoration after antiretroviral therapy: The pitfalls of hasty or incomplete repairs. Immunol. Rev. 2013, 254, 343-354. [CrossRef]

33. d'Ettorre, G.; Ceccarelli, G.; Serafino, S.; Giustini, N.; Cavallari, E.N.; Bianchi, L.; Pavone, P.; Bellelli, V.; Turriziani, O.; Antonelli, G.; et al. Dominant enrichment of phenotypically activated CD38(+) HLA-DR(+) CD8(+) T cells, rather than CD38(+) HLA-DR(+) CD4(+) T cells, in HIV/HCV coinfected patients on antiretroviral therapy. J. Med. Virol. 2016, 88, 1347-1356. [CrossRef]

34. Kuniholm, M.H.; Xie, X.; Anastos, K.; Kaplan, R.C.; Xue, X.; Kovacs, A.; Peters, M.G.; Seaberg, E.C.; French, A.L.; Young, M.A.; et al. Association of Chronic Hepatitis C Infection with T-Cell Phenotypes in HIV-Negative and HIV-Positive Women. J. Acquir. Immune Defic. Syndr. 2014, 67, 295-303. [CrossRef] [PubMed]

35. Medrano, L.M.; Garcia-Broncano, P.; Berenguer, J.; González-García, J.; Jiménez-Sousa, M.Á.; Guardiola, J.M.; Crespo, M.; Quereda, C.; Sanz, J.; Canorea, I.; et al. GESIDA 3603b Study Group. Elevated liver stiffness is linked to increased biomarkers of inflammation and immune activation in HIV/hepatitis C virus-coinfected patients. AIDS 2018, 32, 1095-1105. [CrossRef] [PubMed]

36. Rodríguez-Alba, J.C.; Abrego-Peredo, A.; Gallardo-Hernández, C.; Pérez-Lara, J.; Santiago-Cruz, W.; Jiang, W.; Espinosa, E. HIV Disease Progression: Overexpression of the Ectoenzyme CD38 as a Contributory Factor? Bioessays 2019, 41, e1800128. [CrossRef]

37. Cockerham, L.R.; Jain, V.; Sinclair, E.; Glidden, D.V.; Hartogenesis, W.; Hatano, H.; Hunt, P.W.; Martin, J.N.; Pilcher, C.D.; Sekaly, R.; et al. Programmed death-1 expression on CD4+ and CD8+ T cells in treated and untreated HIV disease. AIDS 2014, 28, 1749-1758. [CrossRef] [PubMed]

38. Hoffman, M.; Pantazis, N.; Martin, G.E.; Hickling, S.; Hurst, J.; Meyerowitz, J.; Willberg, C.B.; Robinson, N.; Brown, H.; Fisher, M.; et al. SPARTAC and CHERUB Investigators. Exhaustion of activated CD8 T cells predicts disease progression in primary HIV-1 infection. PLoS Pathog. 2016, 12, e1005661. [CrossRef]

39. Rallón, N.; García, M.; García-Samaniego, J.; Cabello, A.; Álvarez, B.; Restrepo, C.; Nistal, S.; Górgolas, M.; Benito, J.M. Expression of PD-1 and Tim-3 markers of T-cell exhaustion is associated with CD4 dynamics during the course of untreated and treated HIV infection. PLoS ONE 2018, 13, e0193829. [CrossRef]

40. Khaitan, A.; Unutmaz, D. Revisiting immune exhaustion during HIV infection. Curr. HIV/AIDS Rep. 2011, 8 , 4-11. [CrossRef]

41. Callendret, B.; Walker, C. Immune boost for viral hepatitis. Nat. Med. 2011, 17, 252-253. [CrossRef] 
42. López-Cortés, L.F.; Trujillo-Rodríguez, M.; Báez-Palomo, A.; Benmarzouk-Hidalgo, O.J.; Dominguez-Molina, B.; Milanés-Guisado, Y.; Espinosa, N.; Viciana, P.; Gutiérrez-Valencia, A. Eradication of Hepatitis C Virus (HCV) Reduces Immune Activation, Microbial Translocation, and the HIV DNA Level in HIV/HCV-Coinfected Patients. J. Infect. Dis. 2018, 218, 624-632. [CrossRef]

43. Lin, W.; Weinberg, E.M.; Chung, R.T. Pathogenesis of accelerated fibrosis in HIV/HCV co-infection. J. Infect. Dis. 2013, 207, S13-S18. [CrossRef]

44. Mastroianni, C.M.; Lichtner, M.; Mascia, C.; Zuccalà, P.; Vullo, V. Molecular mechanisms of liver fibrosis in HIV/HCV coinfection. Int. J. Mol. Sci. 2014, 15, 9184-9208. [CrossRef] [PubMed]

45. Perazzo, H.; Veloso, V.G.; Grinsztejn, B.; Hyde, C.; Castro, R. Factors That Could Impact on Liver Fibrosis Staging by Transient Elastography. Int. J. Hepatol. 2015, 2015, 624596. [CrossRef] [PubMed]

46. Wang, L.; Zhu, M.; Cao, L.; Yao, M.; Lu, Y.; Wen, X. Liver Stiffness Measurement Can Reflect the Active Liver Necroinflammation in Population with Chronic Liver Disease: A Real-world Evidence Study. J. Clin. Transl. Hepatol. 2019, 7, 313-321. [CrossRef] [PubMed]

(C) 2020 by the authors. Licensee MDPI, Basel, Switzerland. This article is an open access article distributed under the terms and conditions of the Creative Commons Attribution (CC BY) license (http://creativecommons.org/licenses/by/4.0/). 